\title{
Voltage Sag Profile Analysis for Single Line to Ground Fault Based on Static Impedance Load Model
}

\author{
Lilik Jamilatul Awalin, H. Mokhlis, Fadi Albatsh, Bazilah Ismail, Ibrahim Alhamrouni
}

\begin{abstract}
This paper were carried to investigate the effect of self-impedance and mutual impedance in the estimation of the voltage sag in each node. The voltage sag estimation were carried on the TNB $132 / 11 \mathrm{kV}$ distribution network with a single-line-to-ground fault occur in the network. The result shows that when a high fault impedance occur, the impact of mutual impedance will be less. Impedance-based method have a reasonable accuracy in estimate the voltage sag value for each node in the network. Further work can be continue for fault distance estimation based on the accuracy of voltage sag estimation.
\end{abstract}

Keywords - voltage sag, self impedance, mutual impedance, distribution network

\section{Introduction}

Electric power system in general contains of generation, transmission and distribution of electricity energy [1]. Generation is where the electric is generate either through hydro, wind, coal, and fuel. Transmission is the medium to transmit the electric from one place to another place while distribution is the substation that reduce the amount of voltage through the demand and separate it to the consumer [1]. Distribution is an important part in separating the power to the consumer. Therefore, any insecure connectivity and insulating in distribution system will causes to a major disaster called fault [2].

Based on paper in [3] state that the frequency of fault occurrence is depends on the type of the fault. 85 to 90 percent of fault occur is unsymmetrical fault while symmetrical fault only happened in average thirty to thirty five percent only.

Lilik Jamilatul Awalin

Universiti Kuala Lumpur, International College (ICOLE), Kuala Lumpur Malaysia

H. Mokhlis

University of Malaya, Department of Electrical Engineering

Malaysia

Fadi Albatsh

Universiti Kuala Lumpur, International College (ICOLE) , Kuala Lumpur Malaysia

Bazilah Ismail

Universiti Kuala Lumpur, International College (ICOLE), Kuala Lumpur Malaysia
Various studies have shown that between seventy to ninety percent of fault is occur on the overhead line transmission due to the transient fact. Less than eighty percent of fault is occur in the distribution line system while ten to thirty percent of fault is occur in the branches at distribution line [4]. The impact of fault can be seen in the monitoring node base on voltage sag or voltage dip measurement. Voltage sags are momentary dips in voltage with a magnitude of 0.9 p.u. or below and duration between half a cycle to 1 minute [5]. It is recognized as the most important power quality problem affecting industrial customers because it may cause sensitive equipment like adjustable speed drives and programmable logic controllers to trip, thus affecting industrial production losses. Voltage sags at equipment terminals can be caused by short circuit faults hundreds of kilometers away in the transmission system.

The measurement of a voltage sag is stated as a percentage of the nominal voltage, it is a measurement of the remaining voltage and is stated as a sag to a percentage value. Due to the limitation number of the measurement in the distribution network, the estimation of voltage sag is acquired as a pre-fault calculation method.

On the other hand, most of the fault location method was determine fault point based on each section of the system. Impedance-based method are one of the method which estimate the fault point based on each section. For that reason, impedance based methods are required updating the voltage sag at each feeder. So it is crucial to estimate the voltage sag for each section the distribution system. The method which used impedance based method are mention in papers [6-12]

In order to investigate the accuracy of the updating voltage sag, self and mutual impedance will consider in the algorithm. The accuracy of the voltage sag for each section is identified by comparing the voltage measurement value with the estimation value.

Such occurrences have major economic impact as well as impact on the quality of products or services. Therefore, the detection of voltage sag during faults has become a major effort at many electric utilities and industrial customers worldwide. Voltage sags normally have three possible sources: sudden application of certain loads (motor and transformer connections), direct faults (short circuits, over current, and line faults), and overvoltage induced faults.

\section{Voltage Sag Pattern}

In order to justify the use of voltage sag magnitude for estimation voltage sag in each feeder, studies on the voltage sag profile in the different locations was conducted. For this purpose, faults are created at different nodes. The pattern of 
voltage sag magnitude due to Single Line to Ground Fault at node 4 are shown in the following Figure.

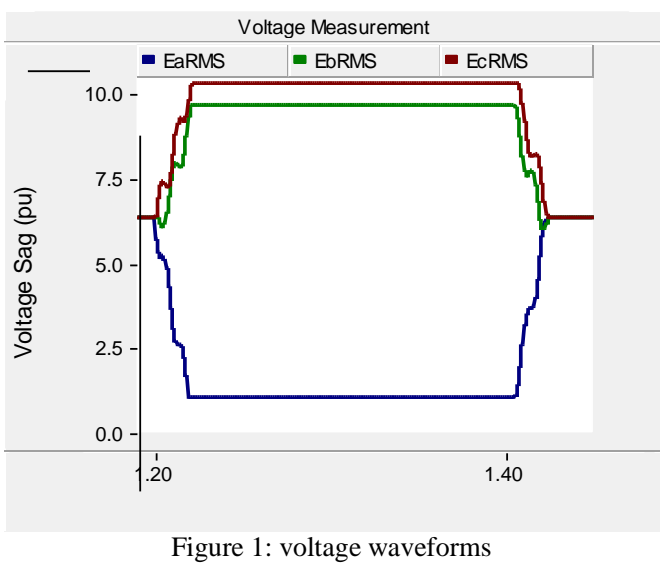

Figure 1 is presenting the voltage sag when fault occur on node 3 as depicture in Figure 3. It can be seen that the voltage magnitude have significant sag due to fault occur in the short distance from the measurement node (node 3). Since SLGF is tested in this research, only voltage in one phase which sag, namely phase A.

\section{Review of Estimation Voltage Sag}

The updating of voltage sag is including voltage sag magnitude and voltage sag angle. The method is discussed from [7,9]. In this paper, analysis of accuracy for voltage sag estimation was utilized Matlab programming. Adopted from [7,9], the author mention about updating voltage sag magnitude and voltage sag angle are shown in equation (3.1). By updating the voltage sag magnitude and angle, the estimation process for detecting the fault location can be carried out. The estimation value for the fault location estimation is generated by using Matlab programming simulation. Since the voltage sag data are only used measurement at the primary substation. An estimation of the voltage value for the incoming node of each line section is needed.

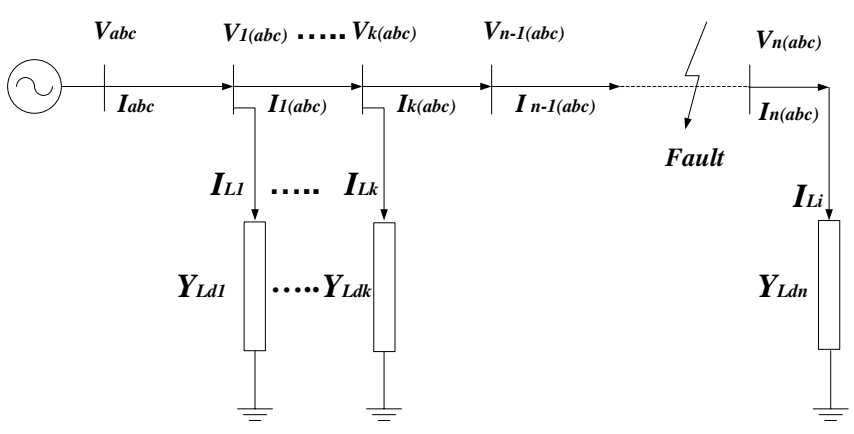

Figure 2. Single-line feeder model [9]

Based on the above figure, the voltage at node $k+1$ can be obtained by using the equation below [9].

$$
V_{k+1}=V_{k}-Z_{k} I_{k}
$$

$$
\left[\begin{array}{l}
V_{L K a} \\
V_{L K b} \\
V_{L K c}
\end{array}\right]=\left[\begin{array}{l}
V_{a} \\
V_{b} \\
V_{c}
\end{array}\right]-\left[\begin{array}{lll}
Z_{a a} & Z_{a b} & Z_{a c} \\
Z_{b a} & Z_{b b} & Z_{b c} \\
Z_{c a} & Z_{c b} & Z_{c c}
\end{array}\right]\left[\begin{array}{l}
I_{K a} \\
I_{K b} \\
I_{K c}
\end{array}\right]
$$

Where :-

$$
\begin{aligned}
& V_{k}=\text { voltage vector at } k \text { th node } \\
& Z_{k}=\text { impedance matrix of } k \text { th line section } \\
& I_{k}=\text { current vector of } k \text { th section }
\end{aligned}
$$

Assuming the constant impedance load, the current flowing out to the $k$ th load tap can be calculated using formula below :

$$
\begin{gathered}
I_{L K}=V_{k} \times Y_{L K} \\
{\left[\begin{array}{l}
I_{L K a} \\
I_{L K b} \\
I_{L K c}
\end{array}\right]=\left[\begin{array}{l}
V_{a} \\
V_{b} \\
V_{c}
\end{array}\right]-\left[\begin{array}{lll}
Y_{a a} & Y_{a b} & Y_{a c} \\
Y_{b a} & Y_{b b} & Y_{b c} \\
Y_{c a} & Y_{c b} & Y_{c c}
\end{array}\right]}
\end{gathered}
$$

Where $I_{L K}$ is the load current vector of $k$ th load tap and $Y_{L K}$ is the load admittance matrix at $k$ th load tap. The current at $k$ th section, $I_{k}$ is given.

$$
I_{k}=I_{k-1}-I_{L k}
$$

Where Self Impedance and mutual impedance are calculate by using equation (3.6) and (3.7):

$$
Z_{A S}=\frac{1}{3}\left(Z_{A 0}+2 Z_{A 1}\right)
$$

and:

Where:

$$
Z_{A M}=\frac{1}{3}\left(Z_{A 0}-Z_{A 1}\right)
$$

$$
\begin{aligned}
& Z_{A S}=\text { self-impedance } \\
& Z_{A M}=\text { mutual impedance } \\
& Z_{A 0}=\text { zero sequence impedance } \\
& Z_{A 1}=\text { positive sequence impedance }
\end{aligned}
$$

After the calculation for obtaining the self-impedance and mutual impedance, the impedances are then used in form of 3-by-3 identity matrix, $Z_{k}$, for further calculation. For the matrix that consider only self-impedance, the value of the self-impedance will be on the diagonal $\left(Z_{a a^{\prime}} Z_{b b}, Z_{c c}\right)$ and everywhere else will be '0' (zero's). Whereas for the matrix that consider both self impedance and mutual impedance, the self impedances value will also be on the diagonal and the mutual impedances value will be on everywhere else as follows.

$$
Z_{k}=\left[\begin{array}{lll}
Z_{a a} & Z_{a b} & Z_{a c} \\
Z_{b a} & Z_{b b} & Z_{b c} \\
Z_{c a} & Z_{c b} & Z_{c c}
\end{array}\right]
$$


Proc. of Sixth International Conference On Advances in Computing, Electronics and Electrical Technology - CEET 2016 Copyright (C) Institute of Research Engineers and Doctors. All rights reserved.

ISBN no. 978-1-63248-109-2 doi: 10.15224/ 978-1-63248-109-2-19

\section{Test Network}

In order to analyze the proposed method performance, a real distribution network, as shown in Figure 3, which belongs to a Malaysian power utility company TNB, is used. This network is connected to the grid via a step down $132 / 11 \mathrm{kV}$ transformer (Y- $\Delta$ ), and it consists of 6 branches, with a total 19 nodes.

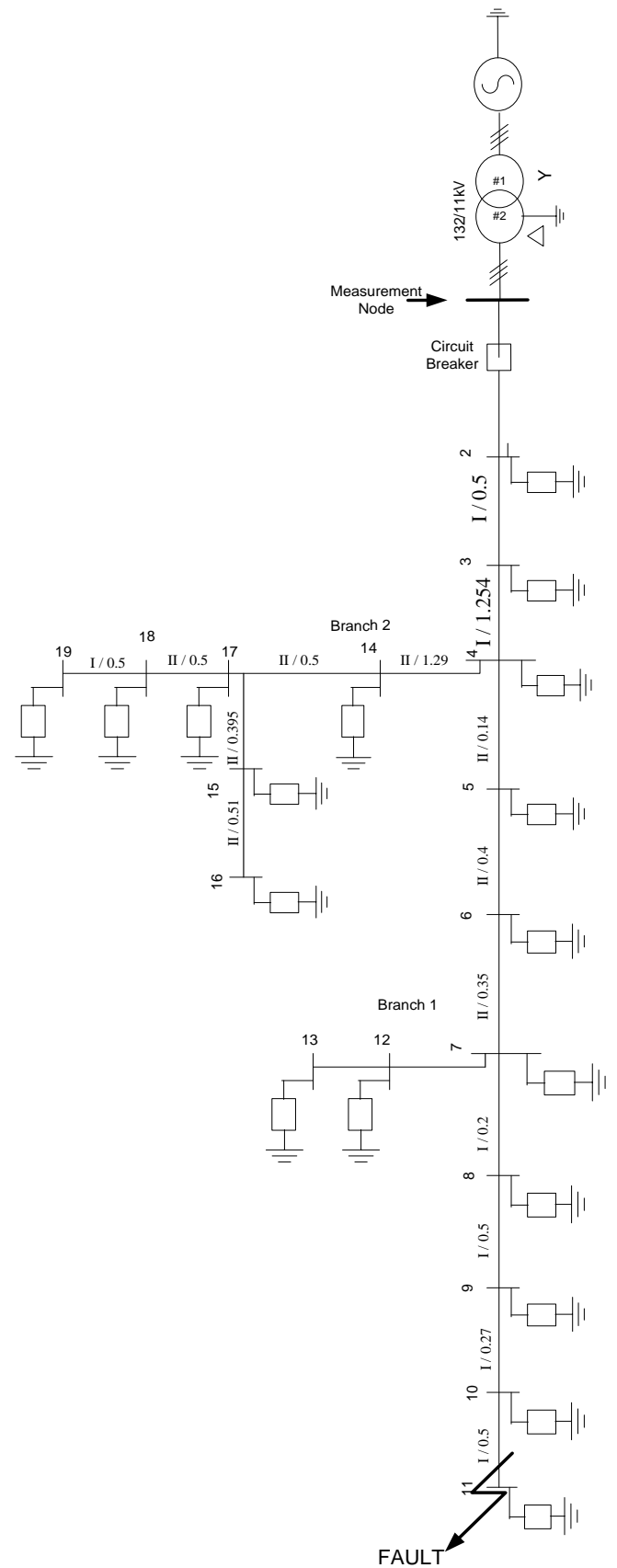

Figure 3. Single Line Diagram of Test Network

\section{v. Result and Discussion}

In this section, the impact of self and mutual impedance are discussed. The various fault impedance also tested. To shows the impact of distance to the accuracy of voltage sag estimation, node 11 is chosen due to have longest distance.

\section{A. Impact of Self and Mutual Impedance}

In this research, the author only consider the single-line-toground fault (phase A) as it is the most often fault occur in the distribution network. The fault were occur on the node 11. For the table of fault impedance $0.01 \mathrm{ohm}$, by considering only self-impedance it give a lower difference between the estimation value with measurement value and a lower percentage of error. This is because the selfimpedance are the real impedance value of the power line especially in a balanced system [10]. Mutual impedance only need to be consider when there are more than one line in parallel position and only when the distribution network is a unbalanced system. Normally the mutual impedance have a differences with the self-impedance in 3 to $7 \%$. Therefore, it can be said that zero sequence of the mutual impedance have a range between 50 to $70 \%$ of the selfimpedance. By that means, the result have a greater differences when considering the mutual impedance in the voltage estimation process when the tested distribution network is a balanced system.

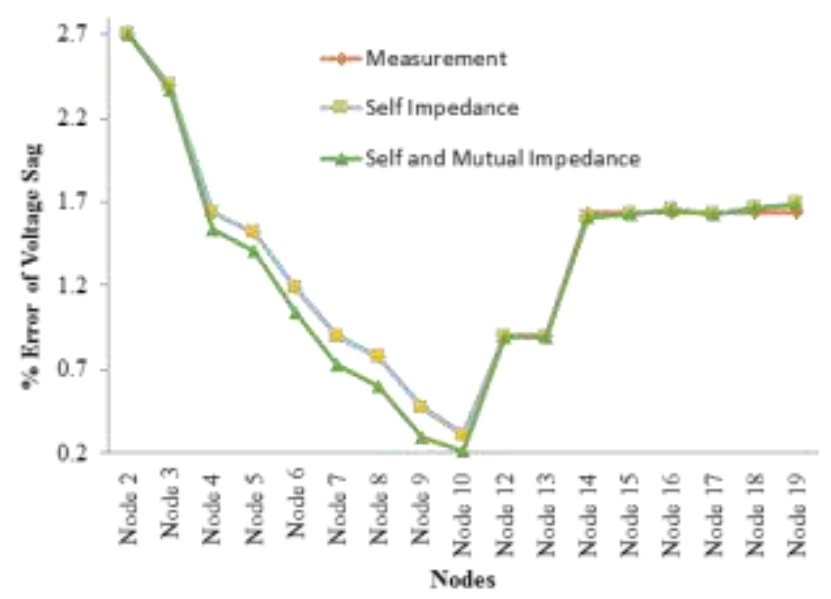

Figure 4. Voltage Estimation Value for Fault Impedance $0.01 \Omega$ at Node 11

\section{B. Impact of Fault Impedance}

From figure 4-5, it shows that the lower fault impedance will create a lower voltage sag value. It follows the principle of Ohm's Law as the lower resistance will create lower voltage as the current gets higher. The effect of the fault impedance in the distribution network is more severe compared to transmission network because of its small short circuit capacity [11]. The fault impedance will influence the type of voltage sag directly to its magnitude and phase angle [12]. 


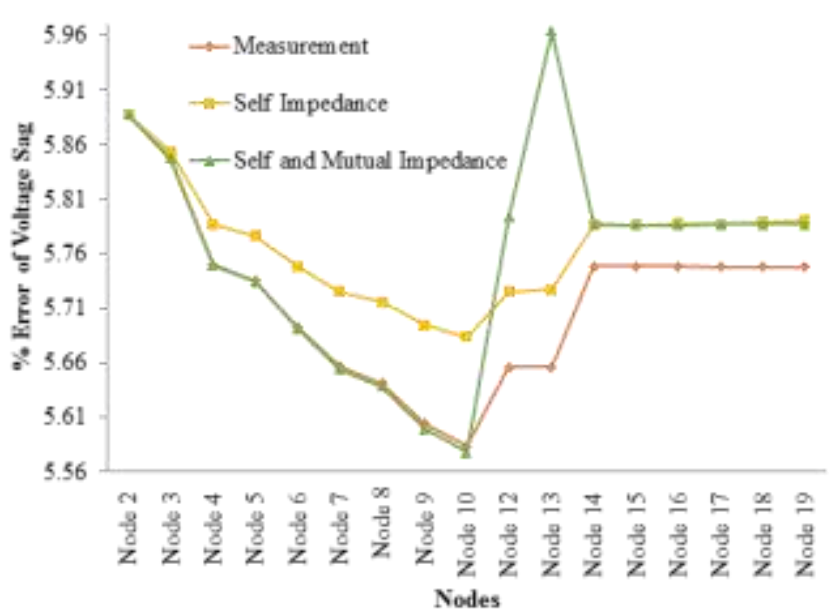

Figure 5. Voltage Estimation Values For Fault Impedance 50 $\Omega$ At Node 11
For table of fault impedance $50 \mathrm{ohm}$, it shows by comparing the voltage value that only consider selfimpedance with both self and mutual impedance, it have a lower differences and lower percentage of error. This is because a higher fault impedance can cause the mutual impedance to be neglected. The basic concept in determining the voltage sag is fault analysis. The voltage sag value in each nodes were determine by the voltage, current and impedance values of the node. Therefore, each node will have a difference value of voltage sag.

\section{Impact of Distance}

For node 2 to node 10 , it shows that the voltage sag value is became lower. The closer node to the faulty node, the lower voltage sag value it will get. This is due to the fact that when voltage sag occur, the current will become higher as the voltage become lower [13]. This reflected to the result shown in the table as the closest node to the faulty node have a greater impact compared to the further node. Nevertheless, for node 12 to node 19, it have a more stable voltage value compare to other nodes because it is located in branches of the distribution network. This is because as the fault occur and voltage sag happen on node 11 , it create an easier path for current to flow from node 2 to node 10 compared with node 12 to node 19 as it has higher impedance which is have only the load impedance.

This is because the fault resistance is lower compared with the network impedances causing a higher value for current to flow to the faulty node. The non-homogenous cable in the distribution network also contributed to the self and mutual impedance value as each section have a difference types of cable.

\section{vI. Conclusion}

Impedance-based method is proven to have a reasonable accuracy in estimating the voltage sag value in the distribution network. This is proven by the result shown as the highest error is only $30 \%$ which is when considering the mutual impedance with a lower fault resistance. This method can be used as a practical solution is estimating the voltage sag value because of its reasonable accuracy and only utilize the measurement at the primary substation. At the end of this research, the effect of self-impedance with mutual impedance and fault resistance value to the voltage sag estimation is known. Higher fault resistance will lower the effect of the mutual impedance in the non-homogenous cable. Due to the result obtained, it can be used for the further works which the fault location determination by using the results. Nevertheless, the accuracy of the voltage sag estimation will influence the accuracy of the fault location determination.

\section{Acknowledgment}

I am greatly thankful for the support from Universiti Kuala Lumpur, International College (ICOLE), Malaysia.

\section{References}

[1] Meier, Alexandra von. Electric Power System, A Conceptual Introduction. A John Wiley and Son, Inc. Publication. (August 2005).

[2] Sadeh, J. Ranjbar, A.M. Hadjsaid, N. R. Feuillet. Accurate Fault Location Algorithm for Power Transmission Lines. Vol. 10, No. 5; (September/October 2000).

[3] Agarwal, Tarun. Types of Fault and Effects in Electrical Power System. Edgefx Technologies Pvt Ltd. (February 2011).

[4] Bakanagari,Satish. Mahesh Kumar, A. Cheenya, M. Three Phase Fault Analysis With Auto Reset for Temporary Fault and Trip for Permanent Fault, Vol. 3 (Issue 6). (December 2013).

[5] IEEE Standard 1159-1995, IEEE Recommended Practice for Monitoring Electric Power Quality

[6] Lilik Jamilatul Awalin, Hazlie Mokhlis, Ab Halim Abu Bakar. (2012) "Recent Development in Fault Location Methods for Distribution Networks".

[7] A. A. Girgis, C. M. Fallon, and D. L. Lubkeman, "A fault location technique for rural distribution feeders," IEEE Trans. Ind. Appl., vol. 29, no. 6, pp. 1170-1175, Nov./Dec. 1993.

[8] Jun Zhu, D.L. Lubkeman, A.A Girgis, "Automated fault location and diagnosis on electric power distribution feeders," Power Delivery, IEEE Transactions on , vol.12, no.2, pp.801-809, Apr 1997

[9] Seung-Jae Lee, Myeon-Song Choi, Sang-Hee Kang, Bo-Gun Jin, Duck-Su Lee, Bok-Shin Ahn, Nam-Seon Yoon, Ho-Yong Kim, Sang-Bong Wee, "An intelligent and efficient fault location and diagnosis scheme for radial distribution systems," Power Delivery, IEEE Transactions on , vol.19, no.2, pp. 524- 532, April 2004

[10] Camilo Andres Roca Duarte and Javier Gustavo Herrera Murcia (2013) " Self and Mutual Transmission Line Impedance Estimation by Means of the Non-linear Least Squares Method".

[11] R. Leal, J. Jacome, J. Blanco, J.F Petit, G. Ordonez and V. Barrera (2008) " Propagation of Voltage Sag: Influence of Transformers, Induction Motors and Fault Resistance.

[12] Pirjo Heine and Matti Lehtonen (2003) "Voltage Sag Distribution Caused by Power System Faults".

[13] Nita R. Patne, Krishna L. Thakre (2008) " Factor Affecting Characteristic of Voltage Sag Due to Faut in the Power System”.

About Author (s):

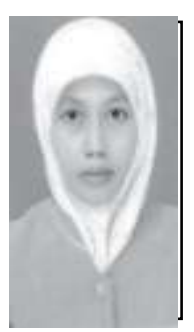

Lilik Jamilatul Awalin was born in East Java, Indonesia, in 1977. She received the B.Eng. degree in electrical engineering in 1999, and the M.Eng. degree in 2004 from Univ. Widya Gama and ITS. She was graduated Ph.D from Universiti of Malaya, 2014. Currently, She is Senior Lecturer in Universiti Kuala Lumpur. Her major research interests include fault location, control system analysis, smart grid, voltage stability and renewable energy. Dr. Lilik J. Awalin is a member of IEEE 


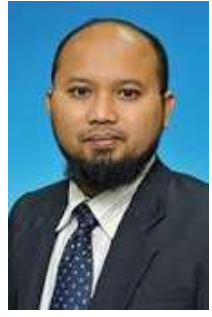

H. Mokhlis received the B. Eng. degree in electrical engineering in 1999, the M. Eng. Sc. degree in 2002 from the University of Malaya (UM), Malaysia, and the Ph.D. degree in 2009 from the University of Manchester, UK. Currently he is a Senior Lecturer with the Department of Electrical Engineering, UM. He is also an associate member of UM Power Energy Dedicated Advanced Research Centre (UMPEDAC), UM. His main research interests include distribution automation and power system protection. Assoc. Prof. Dr. Mokhlis is a member of the IEEE.

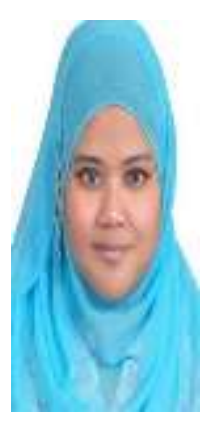

Bazilah Ismail received the BEng in electrical and electronic engineering from University of Sheffield, UK in 2011 and MSc in sustainable electrical engineering from Brunel University London, UK in 2014 respectively. She is currently a lecturer of Electrical Engineering Section at Universiti Kuala Lumpur International College. Her main area of research interests are power quality, power electronics and renewable energy.

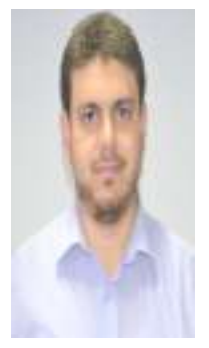

Fadi M. Albatsh received the B.S. and M.S. degrees in Electrical Engineering from the Islamic University of Gaza, Palestine, in 2006 and 2009, respectively. He received $\mathrm{PhD}$ degree from the University of Malaya, Kuala Lumpur, Malaysia in 2015. He is currently Senior Lecturer at Electrical Engineering Section, International College (ICOLE); Universiti Kuala Lumpur .He is the author and co-author of more than 16 publications in an international journals and proceedings in the area of Power Systems and Power Electronics. His research interests include FACTS devices, power converters, power quality, power flow control, voltage stability and renewable energy. 